$12-1-2016$

\title{
Career Decision Self-Efficacy of Transgender People: Pre- and Posttransition
}

lore m. dickey

Daniel Walinsky

Crystal Rofkahr

Kara Richardson-Cline

Cindy L. Juntunen

University of North Dakota, cl.juntunen@UND.edu

How does access to this work benefit you? Let us know!

Follow this and additional works at: https://commons.und.edu/ehb-fac

Part of the Health and Physical Education Commons

\section{Recommended Citation}

lore m. dickey, Daniel Walinsky, Crystal Rofkahr, et al.. "Career Decision Self-Efficacy of Transgender People: Pre- and Posttransition" (2016). Education, Health \& Behavior Studies Faculty Publications. 9.

https://commons.und.edu/ehb-fac/9

This Article is brought to you for free and open access by the Department of Education, Health \& Behavior Studies at UND Scholarly Commons. It has been accepted for inclusion in Education, Health \& Behavior Studies Faculty Publications by an authorized administrator of UND Scholarly Commons. For more information, please contact und.commons@library.und.edu. 


\section{Career Decision Self-Efficacy of Transgender People: Pre- and Posttransition}

Iore m. dickey, Daniel Walinsky, Crystal Rofkahr, Kara Richardson-Cline, Cindy Juntunen

\section{Abstract}

Transgender people often make the decision to change jobs before, during, or after making a social or medical transition. This study explores reported selfefficacy from an online sample of transgender people. Results indicate that there are differences in self-efficacy based on one's gender identity, transition status, and education level. This study offers insight into the important and often overlooked vocational experiences of transgender people. Results suggest ways in which the transition process may interact with career decision self-efficacy.

Although the mental health needs of transgender and gender-nonconforming (TGNC) people have recently been addressed more directly than in the past (Bockting, Miner, Swinburne Romine, Hamilton, \& Coleman, 2013; dickey, Reisner, \& Juntunen, 2015; Meier, Pardo, Labuski, \& Babcock, 2013), there remains a dearth of information related to vocational development of this population. Some of the considerations in career counseling and vocational development among TGNC people include differences in developmental concerns related to gender transition, gender presentation, passing (e.g., being perceived by others in one's affirmed gender), and binary and fluid gender identities (Beemyn \& Rankin, 2011; Harrison, Grant, \& Herman, 2012). In the present study, we consider gender transition with regard to career decision self-efficacy (CDSE) among TGNC people pre- and posttransition.

\section{Gender Identity and the Transgender Umbrella}

The social construct of gender commonly accepted within modern Western and European traditions explicitly links gender to biological sex. In contrast, gender identity reflects an individual's internal experience of themselves as a gendered being (Fausto-Sterling, 2000; Korell \& Lorah, 2007; Lev, 2004). We recognize that the American Psychological Association (APA; 2010) style does not allow for the use of plural pronouns when referring to an individual. However, some TGNC people eschew the gender binary and use gender-neutral pronouns such as they, them, and their. The descriptive category of cisgender describes the group of people whose sex as assigned at birth predominantly corresponds to their gender identity 
(Serano, 2007). When one's sex as assigned at birth and gender identity do not correspond, individuals may identify as transgender (Lev, 2004).

Social scientists have used the term transgender umbrella to refer to the variety of identities that make up the general category of transgender (Fassinger \& Arseneau, 2007; Lev, 2004). Included in this umbrella are identities that would be considered divergent from social constructs of gender that exist on a binary between male and female. Some of the identities include, but are not limited to, transgender (e.g., a person who completes a social transition), transsexual (e.g., a person who has taken medical, surgical, and/or hormonal steps to alter their biological gender identity), male-to-female (MTF), female-to-male (FTM), crossdresser (e.g., a person who dresses in clothing typically associated with the opposite sex), or genderqueer (e.g., a person who does not ascribe to the gender binary). Gender dysphoria is the diagnosis given to some transgender people who seek psychological or psychiatric services and meet the diagnostic criteria in the fifth edition of the Diagnostic and Statistical Manual of Mental Disorders (American Psychiatric Association, 2013) and is commonly treated with hormone therapy and/or gender affirmation surgery (Coleman et al., 2012). Mental health services are often sought because the diagnosis may be a requirement for the minimal available reimbursement for medical treatments. Gender affirmation surgery is a set of surgical procedures that lead to a change in biological gender identity (e.g., MTF or FTM). These surgical procedures include, but are not limited to, breast removal (FTM) or augmentation (MTF) and phalloplasty (FTM) or vaginoplasty (MTF).

Conceptualizing transgender identities along the spectrum of masculine and feminine identities is an imperfect but potentially useful system for classifying and understanding TGNC identities. MTF individuals may present their gender identity along the female spectrum despite having been assigned male at birth. Conversely, FTM individuals may present their gender identity along the male spectrum despite having been assigned female at birth. Neither of these gender identities implies a specific set of gender transition procedures. Rather, they both relate to individuals who live the majority of their lives in a gender other than their sex as assigned at birth.

\section{CDSE}

Self-efficacy beliefs reflect people's specific assessment of their ability or inability to complete a specific task or set of tasks (Bandura, 1977) and are foundational to social cognitive career theory (SCCT; Lent, Brown, \& Hackett, 1994). They are linked to career choice as individuals maintain beliefs about their ability to achieve specific work-related tasks and tend to pursue 
occupations in which they believe they will succeed (Betz \& Hackett, 2006; D. Brown, 2007; Coogan \& Chen, 2007; Lent \& Brown, 2006).

CDSE denotes individuals' perceptions of their ability to successfully complete specific tasks required to make vocational decisions (Fouad, Cotter, \& Kantamneni, 2009). Taylor and Betz (1983) conceptualized CDSE as a multidomain construct that includes accuracy in self-appraisal, vocational knowledge, goal choice, planning, and problem solving. CDSE has been a lens for exploring career decisions among a range of racial, ethnic, and international populations, as well as persons with disabilities (e.g., Buyukgoze-Kavas, 2012; Hayes, Huey, Hull, \& Saxon, 2012; Luzzo, Hitchings, Retish, \& Shoemaker, 1999; Ojeda et al., 2012). In one of the first studies to apply self-efficacy to career decision making, Betz and Hackett (1981) asked 235 college students about their belief in their abilities to achieve in 10 occupations traditionally held by women and 10 occupations traditionally held by men. Results indicated that whereas women rated themselves higher in self-efficacy beliefs related to occupations traditionally held by women and lower in self-efficacy beliefs about occupations traditionally held by men, men maintained higher self-efficacy beliefs about all 20 occupations. Betz and Hackett noted that gender might differentially influence the career development of men and women, and empirical studies have continued to explore the interaction of gender and CDSE. Given the dynamic role of self-efficacy in studies of gender, gender role, and the workplace, extending this work to address career development experiences of TGNC people is a logical next step.

\section{Transgender Vocational Experiences}

Rachlin (2002) suggested that career concerns are primary presenting issues of TGNC people in psychotherapy, yet little research has examined the career concerns of TGNC people (Brewster, Velez, Mennicke, \& Tebbe, 2014; Budge, Tebbe, \& Howard, 2010; Dispenza, Watson, \& Chung, 2012). And, in efforts to be inclusive, vocational researchers have conflated transgender and lesbian, gay, and bisexual (LGB) research topics. This may or may not result in accurate descriptions of transgender experiences (Chung, 2003; T. Israel, 2005). Vocational issues faced by LGB people and transgender people may vary considerably. Many LGB and transgender people report experiences of workplace discrimination (Grant et al., 2011; Pizer, Sears, Mallory, $\&$ Hunter, 2012). However, research has primarily focused on LGB vocational experiences to the exclusion of transgender people (Raggins \& Cornwell, 2001), even though transgender people may encounter specific vocational experiences that merit increased research (Brewster et al., 2014). 
Some TGNC people will make choices related to staying in their jobs or seeking new employment pre- and posttransition. Pepper and Lorah (2008) suggested that the pros and cons of maintaining the same employer pre- and posttransition are framed partially by the underlying fact that transition is a costly process that is rarely covered by insurance. As a result, some TGNC people choose to maintain employment to keep financial options open (G. E. Israel \& Tarver, 1997). Along with providing financial stability during the transition process, an affirming employer with whom a transitioning individual has a strong relationship may provide emotional support and stability during a time of significant change. However, remaining employed at the same place might also result in circumstances in which coworkers struggle to refer to a transitioning individual with proper gender pronouns (Pepper \& Lorah, 2008).

Pepper and Lorah (2008) discussed challenges to the job search process for transgender individuals. For example, TGNC clients may face a potential loss of work history that may accompany transition or name change. Providing a new employer with evidence of previous work history may force a TGNC person to out themselves, leading to potential safety concerns and emotional stress. Another aspect related to transition is the interview process, in which selfconfidence is often seen as a valuable quality. Recently transitioned individuals may be in the process of developing confidence and self-esteem and, as a result, may struggle with a confident presentation during an interview.

Schilt (2006) and Schilt and Connell (2007) analyzed interviews about the pre- and posttransition vocational experiences of postoperative FTM and MTF people. Each study comprised 28 interviews. Findings demonstrate that transitions at the workplace often lead to different perceptions of TGNC workers by others and show different perceptions of the work environment by TGNC people. Findings also revealed that posttransition FTMs often experience the social privileges afforded to men in ways that they had not experienced prior to transition, whereas posttransition MTFs experienced misogyny in vocational settings leading to both heightened social awareness and personal loss of male privilege. Gender transitions in the workplace often led participants to experience overtly gendered reactions on the part of coworkers. Participants found that along with transitioning came new gender-based expectations.

The posttransition experiences described by Schilt and Connell (2007) suggest that transition provides numerous opportunities for individuals to learn about workplace gender behaviors and expectations. These opportunities for learning may translate into increased self-efficacy because they offer chances to perform new tasks successfully. Although neither Schilt and Connell (2007) nor Schilt (2006) specifically explored CDSE, they supported that vocational experiences can be altered positively and negatively by gender transitions. Schilt and Connell also found that, 
after transition, participants' interests were often more aligned with their posttransition gender presentation. Additionally, participants described experiencing more congruence between their interests and the posttransition interactions with coworkers of the same gender. Such affirmations of interests after transitioning may interact with other new learning experiences and increase CDSE for posttransition people considering a career change.

\section{Career Self-Efficacy and Transgender People}

According to SCCT, after an individual examines interests, abilities, and values, career decisions can be made. CDSE is one construct that has been demonstrated to be a reliable predictor of individuals' beliefs in their ability to accomplish tasks typically associated with career-related decisions. CDSE has been studied across various demographic groups (Choi et al., 2012; Jiang, 2014). Although Mau (2000) found a significant interaction between gender and nationality on CDSE scores, in a meta-analysis of CDSE studies, Choi et al. (2012) found no significant gender differences in CDSE scores. Because no studies have empirically examined CDSE of TGNC people pre- and posttransition, the present study aims to fill a major gap in the career counseling literature. Although CDSE is commonly studied along with other vocational variables (e.g., motivation or career maturity), our decision to understand CDSE as a single variable is based on the limited empirical data about ways in which gender transition may influence commonly discussed vocational psychology constructs.

On the basis of findings of increased alignment between posttransition interests and gender presentation (Schilt \& Connell, 2007) and reports of increased comfort in the workplace posttransition (Grant et al., 2011), we hypothesized that posttransition individuals would score higher on the CDSE scale than would individuals who had yet to transition (Hypothesis 1). We also hypothesized that an increase in self-knowledge that is likely to accompany the transition process would translate to higher scores on each of five CDSE components (Hypothesis 2).

\section{Method}

\section{Participants}

Participants were recruited through advertisements in social media outlets frequented by TGNC people (e.g., Facebook, Yahoo! Groups, Trans-Academics) and were asked to complete an online survey hosted by SurveyGizmo. Those included in the study indicated being transgender and at least 18 years of age. Participants completed a demographic form and the Career Decision SelfEfficacy Scale-Short Form (CDSES-SF; Betz, Klein, \& Taylor, 1996). A total of 127 individuals 
completed the survey. The average age of participants was 38.5 years $(S D=13.1)$. For ease of data analysis, participant's gender was categorized as male spectrum (FTM; 45.7\%), female spectrum (MTF; 40.2\%), and genderqueer (14.2\%; percentages do not total 100 because of rounding). Participants were asked about their transition status; $39.2 \%$ reported being pretransition and $60.8 \%$ reported being posttransition. With regard to race, $76.4 \%$ identified as White, $11 \%$ as multiracial, $3.9 \%$ as Hispanic/Latino/Latina, 2.4\% as African American, $1.6 \%$ as Asian, $0.8 \%$ as Native American, and 3.9\% declined to answer this question. Of the participants, $44.8 \%$ indicated they were employed full-time, $14.4 \%$ were employed part-time, $9.6 \%$ were selfemployed, $16.0 \%$ were students, $8.8 \%$ were unemployed, and $6.4 \%$ were either retired or disabled. The sample had varying levels of education, with $40.2 \%$ having less than a college degree (e.g., high school diploma, trade school), 29.9\% holding a bachelor's degree, $29.1 \%$ having a graduate degree (master's or above), and $0.8 \%$ did not answer this question.

\section{Measures}

Sociodemographic characteristics. Participants were asked several questions that addressed demographic characteristics, including age, gender, income, education level, and racial/ethnic identity. Participants were asked about their transition status and were provided the options of pre- or posttransition. Participants were asked about their employment status and were provided the options of employed full-time, employed part-time, self-employed, student, unemployed, retired, and disabled

CDSE. CDSE was measured with the CDSES-SF (Betz et al., 1996). The CDSES-SF is designed to explore college students' perceptions of their ability to make a decision about their vocational lives. The CDSES-SF comprises 25 items, each with a 5-point Likert-type scale with responses ranging from no confidence (1) to complete confidence (5). The CDSES-SF has five subscales that measure distinct constructs related to CDSE: (a) Self-Appraisal, which measures participants' perceptions of their awareness of their own values and abilities and how they relate to career choice (e.g., "accurately assess your abilities"); (b) Occupational Information, which estimates participants' perceived ability to find out important information about specific jobs and industries (e.g., "use the Internet to find information about occupations that interest you"); (c) Goal Selection, which evaluates participants' perceived skills and affective capability to make a decision about occupational choice (e.g., "choose a career that will fit your preferred lifestyle"); (d) Planning, which gauges participants' skills related to the job search and short-term career planning processes (e.g., "prepare a good resume"); and (e) Problem Solving, which measures participants' perceptions of their abilities to overcome obstacles in the career decision process 
(e.g., "change occupations if you are not satisfied with the one you enter"). Each subscale has five items.

Betz, Hammond, and Multon (2005) provided evidence of strong reliability and validity of a five-level short version of the CDSE. The five-level form had alpha values ranging from .78 to .87. The samples used to validate the scale were taken entirely from university students. Basing measurement on university samples may strongly affect external validity. Because the majority of these three samples are White students, generalizability of results to other populations may be compromised (Sue, 2006). Finally, because all participants were university students, they may have a specific knowledge of the world of work or careers that may affect the validity of results related to career self-efficacy. The CDSES-SF has not been normed for TGNC people, and there are no such measures available. We acknowledge that use of the CDSES-SF with a transgender sample may not address the nuanced challenges that TGNC people face in the vocational setting. However, the scale addresses career decision skills that are applicable to transgender and cisgender people.

\section{Data Analysis}

Data analysis was completed using SPSS Version 21. Missing data on the CDSES-SF were replaced with a mean value for other participants on the same item. The data were analyzed to determine frequencies for demographic variables and for the total and subscale scores for the CDSES-SF. We conducted $t$ tests to determine if there were differences in CDSE based on transition or employment status and analysis of variance (ANOVA) to determine if there were differences based on level of education, gender, and CDSE. The significance level for statistical tests was set at .05. The CDSES-SF in the present study showed strong reliability for the full scale (Cronbach's $\alpha=.95$ ).

\section{Results}

Means and standard deviations for the CDSES-SF and employment are presented in Table $\underline{1}$. As indicated by the $t$ tests, mean differences between participants who were employed full-time and those who were not employed full-time were significant only for the Occupational Information subscale, $t(122)=-2.18, p<.05$. Examining the items for the Occupational Information subscale indicated that two items appear to be driving significance of the overall subscale. These items address self-efficacy as it relates to talking with a person in the field of interest, $t(122)=-$ $2.90, p<.01$, and finding a graduate or professional school, $t(122)=-2.44, p<.05$. For transition status, posttransition participants showed statistically significant differences in self- 
efficacy on the total scale score and each of the subscales with the exception of the Goal Selection subscale (see Table $\underline{2}$ ).

Table 1. Means and Standard Deviations for the CDSES-SF by Employment and Transition Status

\begin{tabular}{|c|c|c|c|c|c|c|c|c|}
\hline & \multicolumn{4}{|c|}{ Employment } & \multicolumn{4}{|c|}{ Transition } \\
\hline & $\mathrm{Fu}$ & ne & Not & Time & & & & \\
\hline Scale & $M$ & $S D$ & $M$ & $S D$ & $M$ & $S D$ & $M$ & $S D$ \\
\hline Total & 3.77 & 0.57 & 3.91 & 0.63 & 3.63 & 0.59 & 4.00 & 0.57 \\
\hline Self-Appraisal & 3.74 & 0.61 & 3.91 & 0.68 & 3.67 & 0.58 & 3.95 & 0.67 \\
\hline Occupational Information & 3.86 & 0.63 & 4.11 & 0.65 & 3.70 & 0.65 & 4.20 & 0.57 \\
\hline Goal Selection & 3.69 & 0.62 & 3.79 & 0.74 & 3.59 & 0.72 & 3.84 & 0.65 \\
\hline Planning & 3.87 & 0.67 & 3.99 & 0.82 & 3.66 & 0.72 & 4.12 & 0.72 \\
\hline Problem Solving & 3.68 & 0.68 & 3.74 & 0.76 & 3.50 & 0.71 & 3.90 & 0.69 \\
\hline
\end{tabular}

- $\quad$ Note. CDSES-SF = Career Decision Self-Efficacy Scale-Short Form.

Table 2. $t$ Test Exploring Transition Status and Career Decision-Making Self-Efficacy 
- $\quad$ Note. $N=127$.

- ${ }^{*} p<.05 . * * p<.01$.

We also conducted a $t$ test to examine differences pre- and posttransition in interview skill selfefficacy and found none. Similarly, we conducted an ANOVA with this same question examining differences based on gender, and no significant gender differences emerged. Next, we explored the differences in the Self-Appraisal subscale based on gender by using an ANOVA. Again, there were no statistically significant differences in the mean scores of genderqueer, FTM, and MTF participants. By contrast, the results were significant on this subscale based on a person's reported transition status. People who reported being pretransition $(M=3.67, S D=$ $0.58)$ reported lower Self-Appraisal subscale scores than did posttransition participants $(M=$ $3.95, S D=0.67), t(122)=-2.35, p<.05$.

We also examined differences by education level in self-efficacy as it relates to the Planning and Problem Solving subscales. As seen in Table $\underline{\mathbf{3}}$, the higher the level of education, the greater the 
reported self-efficacy. Post hoc tests revealed that, for the total score and all subscale scores, participants with less than a college degree had statistically significantly less self-efficacy in career decision making. The only subscale for which participants with a bachelor's degree differed significantly from those with a graduate degree was the Goal Selection subscale (mean difference $=0.41, p<.05)$.

Table 3. Results of Analysis of Variance Exploring Differences in Education Level and Career DecisionMaking Self-Efficacy

Scale

Total

Self-Appraisal

Occupational Information

Goal Selection

Planning

Problem Solving
$F(3,121)$

$\eta^{2}$

$10.09 * *$

.14

$5.77^{* *}$

.09

$9.22^{* *}$

10.90**

- Note. $N=125$.

- $\quad * * p<.01$.

\section{Discussion}

Consistent with our hypothesis, posttransition participants demonstrated significantly higher CDSE scores than did pretransition participants on the full-scale CDSES-SF, as well as four of 
the five subscales: Self-Appraisal, Occupational Information, Planning, and Problem Solving. Several explanations help to explain these results and inform future study. One explanation is that through the identity development and transition processes, TGNC people build knowledge and self-awareness that can translate to understanding work life and career choice. Understanding the self as a gendered being is likely to offer insight to TGNC people about how they progress through the world of work. In fact, discussing the likely impact of transition on one's work life fits into the "real-life experience" that used to be a part of the Standards of Care of the World Professional Association of Transgender Health (Coleman et al., 2012) that guide medical and mental health professionals who work with TGNC clients. Yet, any such increase in self-awareness did not translate specifically to higher interview self-efficacy - a domain in which we found no significant differences based on transition status and gender. Career counselors should therefore consider discussing self-efficacy beliefs about interviewing with TGNC clients.

The potential relationship between higher CDSE and increased posttransition self-awareness is highlighted by items on the Self-Appraisal subscale. Self-knowledge that may increase through the transition process might well be applied to the career decision-making process. Similarly, posttransition participants may transfer skills gained through transition, such as managing setbacks and finding solutions to problems in the world of work. For example, the CDSES-SF Problem Solving subscale is composed of items related to ways in which participants manage setbacks and find alternative solutions to problems. Gender transition itself is also a process that is full of logistical, legal, and bureaucratic challenges. It is likely that some of those hurdles create strengths and skills that can be applied to the career decision-making process. Although the barriers at work may be multiple and distinct for TGNC people, the self-awareness gained through the transition process could be a source of strength that can be used in vocational development. This finding should further be viewed in the context of results that show no significant difference in self-appraisal based on gender identity, suggesting that an increase in posttransition self-appraisal may be a common experience across the transgender spectrum.

It is interesting that post hoc analysis showed significantly higher scores on the Occupational Information subscale among participants who did not have full-time employment. This suggests that viewing oneself as capable of finding information about prospective fields necessarily leads to employment. We offer two explanations for this result. First, participants who are more likely to be looking for work may also view themselves as competent in their abilities to find information about different fields and jobs. A second explanation suggests that this finding combined with other data, such as the tendency for transgender people to be better educated than their cisgender counterparts (Factor \& Rothblum, 2007), may be a harsh reminder of the serious 
barriers to obtaining full-time employment faced by TGNC people, despite their levels of education and occupational information self-efficacy.

\section{Implications for Practice}

Results of the present study may be useful for career counselors working with TGNC clients. Viewed in context of other career development literature related to TGNC people, several important themes emerge. For example, although previous studies have highlighted the differential meanings of gender identity and gender roles among TGNC participants (e.g., C. Brown et al., 2012; Sangganjanavanich \& Headley, 2013), our findings did not reflect significant differences based on gender identity. Rather, among participants in this study, significant differences in CDSE were evident based on transition status. This suggests that career counselors who are working with TGNC clients should understand the role and meaning of gender and gender identity with their clients. This is an especially salient consideration for career counselors who commonly work with assessments that have been standardized with male and female cisgender samples. When working with clients who have already started or who have completed a transition, career counselors can integrate self-knowledge gained in the transition process to support vocational development. Helping clients to understand the fit between oneself and a work environment may be especially important for TGNC clients who experience high rates of discrimination at work (Grant et al., 2011). The significantly higher CDSE scores among posttransition participants highlight the importance of understanding concurrent gender identity development and vocational decision-making processes (Budge et al., 2010) and emphasizing intervention that increases CDSE among pretransition clients.

\section{Limitations}

Results of this study should be viewed in the context of several limitations. From a data collection standpoint, we did not ask participants to describe their transitions; rather, we asked if participants had undergone a gender transition. Given the range and differential meanings of gender transition to individuals (Reynolds \& Goldstein, 2014), the distinction between pre- and posttransition can be viewed as more qualitative than categorical, leading to challenges for quantitative researchers. Furthermore, we did not determine the amount of time that had passed since participants completed their transitions. This creates a potential confound, because the length of time since transition may influence participants' perceptions of their self-efficacy broadly, and more specifically, their self-efficacy in the world of work. 
We examined CDSE as the only career-related variable. A more dimensional understanding of self-efficacy surrounding career decisions would better represent the vocational development experiences of TGNC people. Therefore, it would be important to understand how other constructs, such as motivation, self-esteem, and past learning experiences, might influence the development of CDSE among TGNC people. Demographic limitations further limit the generalizability of our results. Although TGNC people have been shown to be highly educated (Factor \& Rothblum, 2007), our sample overrepresented participants who are White and/or have a graduate education.

\section{Directions for Future Research}

Future research focusing on workforce interventions for TGNC people is vital. In terms of CDSE, future study should validate the psychometric properties of the CDSES-SF as a measure used with the TGNC population. Although increasing CDSE is one way to support TGNC career development, it is equally important to intervene systemically. Research that demonstrates the impact of workplace climate on the work lives of TGNC people could support advocacy efforts related to gender diversity in the workplace. The lived vocational experiences of transgender people demonstrate some of the theoretical limitations of applying the CDSES-SF with TGNC populations. For example, if TGNC people leave their job because of discriminatory policy and interpersonal harassment, their performance on the CDSES-SF Self-Appraisal subscale may be disproportionally influenced by both distal and proximal experiences of discrimination (Hendricks \& Testa, 2012). Future research and vocational interventions can support transgender people in identifying and potentially externalizing, rather than internalizing, the impacts of discriminatory actions.

Systems-level research is very important to well-being among TGNC people. However, addressing individual work-life development is also essential. Therefore, resiliency-based research related to transferring the knowledge and skills gained during transition to career development processes is likely to be useful to TGNC people. Moreover, TGNC people are likely to benefit from transferring knowledge and skills gained during transition to increase work-related motivation and support. Career counselors can then integrate skills gained from transition with other factors, such as work history and self-esteem, into conceptualizations.

\section{Conclusion}

Understanding relationships between gender transition and vocational decision making has important implications for research and practice. This study contributes to a growing body of 
empirical literature by highlighting important areas for future study. Furthermore, it suggests the possibility that self-knowledge gained through identity exploration could be applied to increase career self-concept and promote vocational resiliency. Finally, finding higher CDSE among posttransition participants offers further argument for supporting clients who are interested in accessing gender-affirming transition services.

References

American Psychiatric Association. (2013). Diagnostic and statistical manual of mental disorders (5th ed.). Arlington, VA: Author.

American Psychological Association. (2010). Publication manual of the American Psychological Association (6th ed.). Washington, DC: Author.

Bandura, A. (1977). Self-efficacy: Toward a unifying theory of behavioral change. Psychological Review, 84, 191-215. doi:10.1037/0033-295X.84.2.191

Beemyn, G., \& Rankin, S. (2011). The lives of transgender people. New York, NY: Columbia University Press.

Betz, N. E., \& Hackett, G. (1981). The relationship of career-related self-efficacy expectations to perceived career options in college women and men. Journal of Counseling Psychology, 28, 399-410. doi:10.1037/0022-0167.28.5.399

Betz, N. E., \& Hackett, G. (2006). Career self-efficacy theory: Back to the future. Journal of Career Assessment, 14, 3-11. doi:10.1177/1069072705281347

Betz, N. E., Hammond, M. S., \& Multon, K. D. (2005). Reliability and validity of five-level response continua for the Career Decision Self-Efficacy Scale. Journal of Career Assessment, 13, 131-149. doi:10.1177/1069072704273123

Betz, N. E., Klein, K. L., \& Taylor, K. M. (1996). Evaluation of a short form of the Career Decision-Making Self-Efficacy Scale. Journal of Career Assessment, 4, 47-57. doi:10.1177/106907279600400103

Bockting, W. O., Miner, M. H., Swinburne Romine, R. E., Hamilton, A., \& Coleman, E. (2013). Stigma, mental health, and resilience in an online sample of the U.S. transgender population. American Journal of Public Health, 103, 943-951. doi:10.2105/AJPH.2013.301241

Brewster, M. E., Velez, B. L., Mennicke, A., \& Tebbe, E. (2014). Voices from beyond: A thematic content analysis of transgender employees' workplace experiences. Psychology of Sexual Orientation and Gender Diversity, 1, 159-169. doi:10.1037/sgd0000030

Brown, C., Dashjian, L. T., Acosta, T. J., Mueller, C. T., Kizer, B. E., \& Trangsrud, H. B. (2012). The career experiences of male-to-female transsexuals. The Counseling Psychologist, 40, 868-894. doi:10.1177/0011000011430098

Brown, D. (2007). Career information, career counseling, and career development. Boston, MA: Pearson.

Budge, S. L., Tebbe, E. N., \& Howard, K. A. S. (2010). The work experiences of trans-gender individuals: Negotiating the transition and career decision-making process. Journal of Counseling Psychology, 57, 377-393. doi:10.1037/a0020472 
Buyukgoze-Kavas, A. (2012). A psychometric evaluation of the Career Decision Self-Efficacy Scale-Short Form with Turkish university students. Journal of Career Assessment, 22, 386-397. doi:10.1177/1069072713484561

Choi, B. Y., Park, H., Yang, E., Lee, S. K., Lee, Y., \& Lee, S. M. (2012). Understanding career decision self-efficacy: A meta-analytic approach. Journal of Career Development, 39, 443-460. doi:10.1177/0894845311398042

Chung, Y. B. (2003). Career counseling with lesbian, gay, bisexual, and transgen-der persons: The next decade. The Career Development Quarterly, 52, 78-86. doi:10.1002/j.21610045.2003.tb00630.x

Coleman, E., Bockting, W., Botzer, M., Cohen-Kettenis, P., DeCuypere, G., Feldman, J., . . . Zucker, K. (2012). Standards of care for the health of transsexual, transgender, and gender nonconforming people, 7th version. International Journal of Transgenderism, 13, 165-232. doi:10.1080/15532739.2011.700873

Coogan, P. A., \& Chen, C. P. (2007). Career development and counseling for women: Connecting theories to practice. Counseling Psychology Quarterly, 20, 191-204. doi:10.1080/09515070701391171

dickey, 1. m., Reisner, S. L., \& Juntunen, C. L. (2015). Non-suicidal self-injury in a large online sample of transgender adults. Professional Psychology: Research and Practice, 46, 3-11. doi: $10.1037 / \mathrm{a} 0038803$

Dispenza, F., Watson, L. B., \& Chung, Y. B. (2012). Experience of career-related discrimination for female-to-male transgender persons: A qualitative study. The Career Development Quarterly, 60, 65-81. doi:10-1002/j.2161-0045.2012.00006.x

Factor, R. J., \& Rothblum, E. D. (2007). A study of transgender adults and their non-transgender siblings on demographic characteristics, social support and experiences of violence. Journal of LGBT Health Research, 3, 11-30. doi:10.1080/15574090802092879

Fassinger, R. E., \& Arseneau, J. R. (2007). "I'd rather get wet than be under that um-brella": Differentiating the experiences and identities of lesbian, gay, bisexual, and transgender people. In K. J. Bieschke, R. M. Perez, \& K. A. DeBord (Eds.), Handbookof counseling and psychotherapy with lesbian, gay, bisexual, and transgender clients (2nd ed., pp. 19-50). Washington, DC: America Psychological Association.

Fausto-Sterling, A. (2000). Sexing the body. New York, NY: Basic Books.

Fouad, N., Cotter, E. W., \& Kantamneni, N. (2009). The effectiveness of a career decisionmaking course. Journal of Career Assessment, 17, 338-347. doi:10.1177/1069072708330678

Grant, J. M., Mottet, L. A., Tanis, J., Harrison, J., Herman, J. L., \& Kiesling, M. (2011). Injustice at every turn: A report of the National Transgender Discrimination Survey. Washington, DC: National Center for Transgender Equality \& National Gay and Lesbian Task Force. Retrieved from http://endtransdiscrimination.org/PDFs/NTDS_Report.pdf

Harrison, J., Grant, J., \& Herman, J. L. (2012). A gender not listed here: Genderqueers, gender rebels, and otherwise in the National Transgender Discrimination Study. LGBTQ Policy Journal at the Harvard Kennedy School, 2, 13-24.

Hayes, D., Huey, E. L., Hull, D. M., \& Saxon, T. F. (2012). The influence of youth assets on the career decision self-efficacy in unattached Jamaican youth. Journal of Career Development, 39, 407-422. doi:10.1177/0894845310390364

Hendricks, M. L., \& Testa, R. J. (2012). A conceptual framework for clinical work with transgender and gender nonconforming clients: An adaptation of the minority stress 
model. Professional Psychology: Research and Practice, 43, 460-467.

doi:10.1037/a0029597

Israel, G. E., \& Tarver, D. E. (1997). Transgender care: Recommended guidelines, practical information and personal accounts. Philadelphia, PA: Temple University.

Israel, T. (2005, Summer). . . a and sometimes T: Transgender issues in LGBT psychology. Newsletter of the Society for the Psychological Study of Lesbian, Gay, and Bisexual Issues, 21, 16-18.

Jiang, Z. (2014). Emotional intelligence and career decision-making self-efficacy: National and gender differences. Journal of Employment Counseling, 51, 112-124. doi:10.1002/j.2161-1920.2014.00046.x

Korell, S. C., \& Lorah, P. (2007). An overview of affirmative psychotherapy and counseling with transgender clients. In K. J. Bieschke, R. M. Perez, \& K. A. DeBord (Eds.), Handbookof counseling and psychotherapy with lesbian, gay, bisexual, and transgender clients (2nd ed., pp. 271-288). Washington, DC: American Psychological Association.

Lent, R. W., \& Brown, S. D. (2006). On conceptualizing and assessing social cognitive constructs in career research: A measurement guide. Journal of Career Assessment, 14, 12-35. doi:10.1177/1069072705281364

Lent, R. W., Brown, S. D., \& Hackett, G. (1994). Toward a unifying social cognitive theory or career and academic interest, choice, and performance. Journal of Vocational Behavior, 45, 79-122. doi:10.1006/jvbe.1994.1027

Lev, A. I. (2004). Transgender emergence: Therapeutic guidelines for working with gendervariant people and their families. New York, NY: Haworth Press.

Luzzo, D. A., Hitchings, W. E., Retish, P., \& Shoemaker, A. (1999). Evaluating differences in college students' career decision making on the basis of disability status. The Career Development Quarterly, 48, 142-156. doi:10.1002/j.2161-0045.1999.tb00281.x

Mau, W.-C. (2000). Cultural differences in career decision-making styles and self-efficacy. Journal of Vocational Behavior, 57, 365-378. doi:10.1006/jvbe.1999.1745

Meier, S. C., Pardo, S. T., Labuski, C., \& Babcock, J. (2013). Measures of clinical health among female-to-male transgender persons as a function of sexual orientation. Archives of Sexual Behavior, 42, 463-474. doi:10.1007/s10508-012-0052-2

Ojeda, L., Piña-Watson, B., Castillo, L. G., Castillo, R., Khan, N., \& Leigh, J. (2012). Acculturation, enculturation, ethnic identity, and conscientiousness as predictors of Latino boys' and girls' career decision self-efficacy. Journal of Career Development, 39,208-229. doi:10.1177/0894845311405321

Pepper, C. H., \& Lorah, P. (2008). Career issues and workplace considerations for the transsexual community: Bridging a gap of knowledge for career counselors and mental health care providers. The Career Development Quarterly, 56, 330-343. doi:10.1002/j.2161-0045.2008.tb00098.x

Pizer, J. C., Sears, B., Mallory, C., \& Hunter, N. D. (2012). Evidence of persistent and pervasive workplace discrimination against LGBT people: The need for federal legislation prohibiting discrimination and providing for equal employment benefits. Loyola of Los Angeles Law Review. Retrieved from http://williamsinstitute.law.ucla.edu/wpcontent/uploads/Pizer-Mallory-Sears-Hunter-ENDA-LLR-2012.pdf

Rachlin, K. (2002). Transgender individuals experiences of psychotherapy. International Journal of Transgenderism, 6(1). 
Raggins, B. R., \& Cornwell, J. M. (2001). Pink triangles: Antecedents and consequences of perceived workplace discrimination against gay and lesbian employees. Journal of Applied Psychology, 86, 1244-1261. doi:10.1037/0021-9010.86.6.1244

Reynolds, H. M., \& Goldstein, Z. G. G. (2014). Social transition. In L. Erickson-Schroth (Ed.), Trans bodies, trans selves: A resource for the transgender community (pp. 124-155). New York, NY: Oxford University Press.

Sangganjanavanich, V. F., \& Headley, J. A. (2013). Facilitating career development concerns of gender transitioning individuals: Professional standards and competencies. The Career Development Quarterly, 61, 354-366. doi:10.1002/j.2161-0045.2013.00061.x

Schilt, K. (2006). Just one of the guys? How transmen make gender visible at work. Gender and Society, 20, 465-490. doi:10.1177/0891243206288077

Schilt, K., \& Connell, C. (2007). Do workplace gender transitions make gender trouble? Gender, Work, \& Organization, 14, 596-618. doi:10.1111/j.1468-0432.2007.00373.x

Serano, J. (2007). Whipping girl: A transsexual woman on sexism and the scapegoating of femininity. Berkeley, CA: Seal Press.

Sue, S. (2006). Science, ethnicity, and bias: Where have we gone wrong? In A. E. Kazdin (Ed.), Methodological issues and strategies in clinical research (3rd ed., pp. 173-188). Washington, DC: American Psychological Association.

Taylor, K. M., \& Betz, N. E. (1983). Applications of self-efficacy theory to the understanding and treatment of career indecision. Journal of Vocational Behavior, 22, 63-81. doi:10.1016/0001-8791(83)90006-4 